\title{
Inhibition of BRD4 Suppresses Cell Proliferation and Induces Apoptosis in Renal Cell Carcinoma
}

\author{
Xinchao Wua,b Dong Liu ${ }^{a}$ Xuemei Gao Fei Xie ${ }^{a}$ Dan Tao ${ }^{c}$ Xingyuan Xiao \\ Liang Wanga Guosong Jianga Fuqing Zenga $^{a}$
}

aDepartment of Urology, Union Hospital, Tongji Medical College, Huazhong University of Science and Technology, Wuhan, bDepartment of Urology, The First Affiliated Hospital of Zhengzhou University, Zhengzhou, 'Department of Oncology, The Fifth Hospital of Wuhan, Wuhan, China

\section{Key Words}

BRD4 • JQ1 • Renal cell carcinoma $\cdot$ Apoptosis $•$ Cell proliferation

\begin{abstract}
Background/Aims: Renal cell carcinoma (RCC) remains an intractable genitourinary malignancy. Resistance to chemotherapy or targeted therapies in RCC is presumably due to the complicated underlying molecular mechanisms and insufficient understanding. The aim of this research was to assess the expression and role of bromodomain-4 protein (BRD4) in RCC and evaluate the effects of BRD4 inhibitor JQ1 for RCC treatment. Methods: BRD4 expressionlevels were assessed by qRT-PCR and western blot in RCC tissues and cells. The effects of BRD4 knockdown or JQ1 on RCC cells were assessed by MTT assay and flow cytometry. The effects of in vivo treatment were evaluated through xenograft experiments. Results: BRD4 is significantly overexpressed in RCC, and is related to tumor stage and lymph node metastasis. Inhibition of BRD4 suppressed RCC cell proliferation, induced cell apoptosis in vitro and repressed tumor growth in vivo. Inhibition of BRD4 decreased BCL2 and C-MYC expression while increased BAX and cleaved caspase3 expression, and strikingly diminished the recruitment of BRD4 to BCL2 promoter. Conclusions: Our research reveals that BRD4 probably play a critical role in RCC progression, and is a new promising target for pharmacological treatment directed against this intractable disease.

\section{Introduction}

Renal cell carcinoma (RCC) is a common genitourinary malignancy with an incidence of about $5-10$ per 100,000 , which accounts for $2-3 \%$ of all tumors in adults [1]. Clear cell renal cell carcinoma (ccRCC), the most common type of renal cancer, is responsible for about

$\mathrm{X}$. Wu and D. Liu contributed equally to this work. 
$75 \%$ of cases [2]. Despite recent advances in treatment, RCC remains a virtually intractable disease. The incidence of this cancer has steadily increased in recent years, contributing to an increasing mortality rate worldwide. What is worse, apart from surgery, RCC is resistant tochemotherapy and radiotherapy [3]. The 5-year cancer-specific survival of RCC remains at approximately 55\%, and current therapeutic efficacy is far from satisfactory [4]. To date, although a series of genetic and epigenetic changes have been reported to be correlated with these tumors, the pathogenesis and genetic regulatory networks remains poorly understood [5]. Therefore, it is still necessary to find new gene dysregulations and identify novel therapeutic targets in RCC.

As well-known and classical epigenome readers, the bromodomain and extra terminal (BET) protein family constitutes a series of proteins characterized by two conserved bromodomains (BD1 and BD2) and is reported to exert important roles in inflammation, tumor development and several other diseases [6-9]. The N-terminal bromodomains are chromatin interaction modules that enable to recognize acetylated lysine residues in histones and other nuclear proteins [10]. Bromodomain-containing protein 4 (BRD4) is an important and emphatically studied member of the BET family, which is frequently reported to aberrantly expressed in several cancers and related to cancer cell growth regulation, although the potential molecular regulation mechanisms have been incompletely elucidated [11-14]. Recently, several synthesized small-molecule chemical compounds targeting BET proteins have been developed to demonstrate the anti-tumor effects in a number of malignancies. The specific small BET inhibitors have exhibited apparent efficacy in suppressing tumor progression in a series of cancer models [15-18]. However, the role of BRD4 protein in RCC is still poorly studied, and the therapeutic effect of BET inhibitor in RCC treatment has yet to be described.

In the present study, we evaluated the role of BRD4 in RCC and investigated the anticancer effects of BET inhibitors in vitro and in vivo. We exhibited the notable effect of BET inhibitor on cell biological activity and tumor growth in RCC. Collectively, our research demonstrates a potential requirement for BRD4 protein in RCC maintenance and supports a novel therapeutic strategy for RCC treatment.

\section{Materials and Methods}

\section{Cell lines and human tissue specimens}

The human ACHN and 786-0 RCC cell lines were obtained from American Type Culture Collection (ATCC, Manassas, VA, USA), and were maintained in DMEM medium (Gibco, Grand Island, NY, USA) and RPMI 1640 medium (Gibco), respectively. The human renal tubule epithelial cell line HK-2 was purchased from ATCC as well and was maintained in complete medium containing keratinocyte serum-free medium (K-SFM). The cells were maintained in the appropriate medium at $37^{\circ} \mathrm{C}$ and supplied with $5 \% \mathrm{CO}_{2}$. Forty pairs of renal cell carcinoma samples and surrounding normal adjacent kidney tissues were collected from patients who underwent nephrectomy at Department of Urology of the Union Hospital of Tongji Medical College between 2013 and 2014. Histological and pathological diagnoses were authenticated by two pathologists. Clinicopathological characteristics in the study are exhibited in Table 1. Approval for this research was obtained from the Institutional Review Board of Tongji Medical College of Huazhong University of Science and Technology, and informed consent was received from the corresponding patients before surgery.

\section{Plasmid construction and transfection}

Four BRD4-targeted candidate shRNAs and negative control were designed and synthesized by Genechem. The target sequences of the knockdown constructs of BRD4 are presented as follows: TCCGATTGATGTTCTCCAA (shBRD4-1), TGGAGATGACATAGTCTTA (shBRD4-2), CTGATTACTATAAGATCAT (shBRD4-3), and CTATGTCCTATGAGGAGAA (shBRD4-4). Cells were seeded in 6-well plates with 40-60\% confluence $24 \mathrm{~h}$ before transfection to allow attachment. Lipofectamine 2000 (Invitrogen, USA) was used as the transfection reagent. The supernatant was replaced by fresh culture medium after 4-6h of transfection. Stable knockdown cell lines were screened by puromycin (Invitrogen). 
Table 1. Correlation between BRD4 expression and clinicopathological characteristics in patients with $\mathrm{RCC} .{ }^{*} \mathrm{P}<0.05$

\begin{tabular}{|c|c|c|c|c|c|}
\hline \multirow{2}{*}{ Parameters } & \multirow{2}{*}{ Group } & \multirow{2}{*}{ Total } & \multicolumn{2}{|c|}{ BRD4 expression } & \multirow{2}{*}{$P$ value } \\
\hline & & & High & Low & \\
\hline \multirow[t]{2}{*}{ Gender } & Male & 22 & 12 & 10 & 1.000 \\
\hline & Female & 18 & 10 & 8 & \\
\hline \multirow[t]{2}{*}{ Age (years) } & $<65$ & 21 & 10 & 11 & 0.360 \\
\hline & $\geq 65$ & 19 & 12 & 7 & \\
\hline \multirow[t]{2}{*}{ Tumor size } & $<4.0 \mathrm{~cm}$ & 25 & 13 & 12 & 0.747 \\
\hline & $>4.0 \mathrm{~cm}$ & 15 & 9 & 6 & \\
\hline \multirow[t]{2}{*}{ Histological grade } & I-II & 26 & 13 & 13 & 0.510 \\
\hline & III-IV & 14 & 9 & 5 & \\
\hline \multirow[t]{2}{*}{ Tumor stage } & T1-T2 & 31 & 14 & 17 & $0.027 *$ \\
\hline & T3-T4 & 9 & 8 & 1 & \\
\hline \multirow[t]{2}{*}{ Lymph nodes metastasis } & Absence & 26 & 10 & 16 & $0.007 *$ \\
\hline & Presence & 14 & 12 & 2 & \\
\hline \multirow[t]{2}{*}{ Distant metastasis } & Absence & 34 & 18 & 16 & 0.673 \\
\hline & Presence & 6 & 4 & 2 & \\
\hline
\end{tabular}

Real-time PCR analysis

Trizol reagent (Invitrogen) was used to isolate RNA from cell lines and tissues according to the manufacturer's instructions. Random primers were used to synthesize the complementary DNA (cDNA). Quantitative real-time PCR (qPCR) was carried out on StepOnePlus (Life Technologies) apparatus. The primers are designed as follows: BRD4: 5'-GTGGGAGGAAAGAAACAGGGACA-3' (forward) and 5'-AGGAGGAGGATTCGGCTGAGG-3' (reverse), BCL2: 5'-AGTACCTGAACCGGCACCT-3' (forward) and 5'CAGCCAGGAGAAATCAAACAG-3' (reverse), C-MYC: 5'-AGGGATCGCGCTGAGTATAA-3' (forward) and 5'-TGCCTCTCGCTGGAATTACT-3' (reverse), GAPDH:5'-TCAAGAAGGTGGTGAAGCAG-3' (forward) and 5'-CGTCAAAGGTGGAGGAGTG-3' (reverse). Results were normalized to GAPDH and calculated using the $\triangle \triangle \mathrm{CT}$ method.

\section{Western blot analysis}

Protein lysates were treated with RIPA buffer (Thermo Scientific, Rockford, IL, USA) containing protease inhibitor cocktail (Beyotime Institute of Biotechnology, Haimen, China). A BCA protein assay kit (Beyotime) was used to determine the concentration of protein samples. The lysates were separated by $10 \%$ SDS-PAGE and were then transferred to PVDF membranes. Tris-buffered saline (TBS) containing 5\% nonfat skim milk was then used to block the membranes for $1 \mathrm{~h}$ and primary antibodies of human BRD4 (ab128874, Abcam), BCL2 (ab7973, Abcam), C-MYC(ab39688, Abcam), BAX (ab32503, Abcam), mouse antihuman caspase-3 (ab2302, Abcam), or GAPDH (D16H11, Cell Signaling Technology Inc.) were probed at $4^{\circ} \mathrm{C}$ for $12 \mathrm{~h}$. And the membranes were incubated with corresponding specific HRP-conjugated secondary antibodies (Wuhan Boster Bio-engineering Limited Company, China) subsequently for $2 \mathrm{~h}$ followed by developing with the ECL kit (Beyotime). Image J Software was performed for data analysis to evaluate the relative expression levels of the proteins.

\section{Cell viability assay by MTT}

Cell viability was determined by MTT assay. Cells were seeded in 96-well plate at a density of 5000 cells/0.1 mL per well. After shRNA transfection or drug treatment, $20 \mu \mathrm{L}$ of MTT solution was added to each well and then the plate was incubated at $37^{\circ} \mathrm{C}$ for another $4 \mathrm{~h}$ in dark. Then discard the supernatant and add $100 \mu \mathrm{L}$ of DMSO to dissolve the precipitate. The optical density (OD) of formazan was detected at $490 \mathrm{~nm}$ to estimate the cell viability.

Flow cytometry assay for cell cycle and cell apoptosis

786-0 and ACHN cells were treated with JQ1 (Selleckchem) or transfected with shRNAs. After transfection or drug treatment, cells were harvested for cell cycle analysis, and then fixed in $70 \%$ ethanol at $4^{\circ} \mathrm{C}$ overnight. Subsequently cells were washed with PBS and stained with propidium iodine (PI, Sigma, St Louis, MO, USA) for 30 minutes, followed by flow cytometry analysis. Cells were harvested for apoptosis 


\section{Cellular Physiology Cell Physiol Biochem 2017;41:1947-1956 and Biochemistry Published onIne: AprI 07, $2017 \quad \begin{aligned} & \text { DOI: 10.1159/000472407 } 2017 \text { The Author(s). Published by S. Karger AG, Basel } \\ & \text { www.karger.com/cpb }\end{aligned}$}

Wu et al.: BRD4 is a Novel Therapeutic Target in RCC

assay using the Annexin-V-PI ptosis detection kit (BD Pharmingen, SanDiego, CA, USA) according to the manufacturer's directions.

Tumor xenografts and in vivo treatment

All animal experiments were approved by the Animal Care Committee of Tongji Medical College. ACHN cells $\left(1 \times 10^{7} / 100 \mu \mathrm{L}\right.$ PBS $)$ were injected into 3-4 weeks old nude mice to achieve tumor growth. When the tumor size reached a palpable stage, the animals were randomly devided in two groups ( $\mathrm{n}=10 /$ group) for JQ1 treatment trials. JQ1 dissolved in DMSO was then diluted by dropwise addition of 2-hydroxypropyl-bcyclodextrin carrier (Sigma). The mice were treated intraperitoneally with either diluted JQ1 (50 mg/kg) or vehicle containing 5\% DMSO every day. For the shRNA experiments, stable ACHN cells $\left(1 \times 10^{7}\right)$ transfected with BRD4 shRNA or control constructs screened by puromycin were intraperitoneally injected into mice ( $n=10$ /group). Tumor volume was evaluated every three days using Vernier calipers and then calculated with the equation: length $\times$ width ${ }^{2} \times 0.5$. Three weeks later, the mice were killed simultaneously. Then tumors were subsequently excised, photographed and weighed.

Chromatin immunoprecipitation (ChIP) assay

The ChIP experiment was performed with the EZ-ChIP kit (Upstate Biotechnology, Lake Placid, NY, USA) according to the manufacturer's instructions. Real-time PCR primers for the BCL2 promoter were designed and synthesized to amplify the corresponding regions (-1233 -1025) upstream the transcription start site (Fig. 3G). The primers for BCL2 promoter: 5'-ACACACGTCTGCGAGTGTGAATGT-3' (Forward); 5'-TCCCTCTGTCCCTAACACCTTT-3' (Reverse). The SYBR ${ }^{\circledR}$ Premix Ex Taq ${ }^{\mathrm{TM}}$ kit was then used for qPCR amplification with the StepOnePlus Real-Time PCR System. IgG was used as a negative control within each group. The amount of immunoprecipitated DNA was evaluated by generating a standard curve and normalized against the shNC control group or the DMSO control group.

\section{Statistical analysis}

Statistical Package for the Social Sciences (SPSS) software (version 13.0, SPSS Inc., Chicago, IL, USA) and GraphPad Prism (Version 5, La Jolla, CA, USA) were used for data analyses. For the analysis of clinicopathological factors and mRNA expression of BRD4, BRD4 expression in tumor specimen was divided by that in paired normal kidney tissues (T/N expression ratio). Specimen were classified into two groups, the high expression group having a $\mathrm{T} / \mathrm{N}>2$ while the low expression group having a $\mathrm{T} / \mathrm{N} \leq 2$. $\mathrm{T}$-tests were applied to evaluate the difference between paired tissue specimens. All tests were two-sided, $\mathrm{P}<0.05$ was considered statistical significant.

\section{Results}

BRD4 is overexpressed in RCC tissue specimens and cell lines

Forty pairs of RCC samples and adjacent normal kidney tissues were collected to evaluate the relative expression level of BRD4. As shown in Figure 1 (1A and 1B), both mRNA and protein levels of BRD4 were markedly upregulated in RCC when compared with adjacent normal kidney tissues $(\mathrm{P}<0.05)$. A relationship was revealed between BRD4 expression and cancer stage $(\mathrm{P}<0.05)$ and lymph nodes metastasis $(\mathrm{P}<0.05$, Table 1$)$. Moreover, upregulation of BRD4 was also confirmed in the RCC 786-O and ACHN cell lines as compared with HK-2 cells (Fig. 1, C and D). These results suggested that BRD4 protein potentially play an important role in promoting RCC progression.

BRD4 inhibition suppresses cell proliferation and induces cell apoptosis in RCC

Given that BRD4 is upregulated in RCC tissues and cell lines in our study, we further investigate the effect of BRD4 inhibition on RCC cell lines. Four shRNAs targeting the coding region of BRD4 (shBRD4) were synthesized and transfected into cells (Fig. 2A). As shown in Figure 2 (B and C), BRD4 mRNA and protein levels were markedly silenced by transfection of shBRD4 in 786-0 and ACHN cells. We eventually selected shBRD4-3 and shBRD4-4 for further studies owing to the prominent knockdown effects. After shRNAs transfection or 
Fig. 1. BRD4 is up-regulated in RCC tissues and cell lines. We evaluated the relative mRNA and protein levels of BRD4 in human RCC tissues by real-time PCR (A) and western blot (B). The transcriptional expression of BRD4 in human proximal tubule epithelial cell line (HK-2) and RCC cell lines (786-O and ACHN) are exhibited in C. The corresponding protein levels are showed in D. GAPDH was used as the internal control. ${ }^{*} \mathrm{P}<0.05$ compared with the $\mathrm{HK}-2$ cells. Results are the means $\pm \mathrm{SD}$.
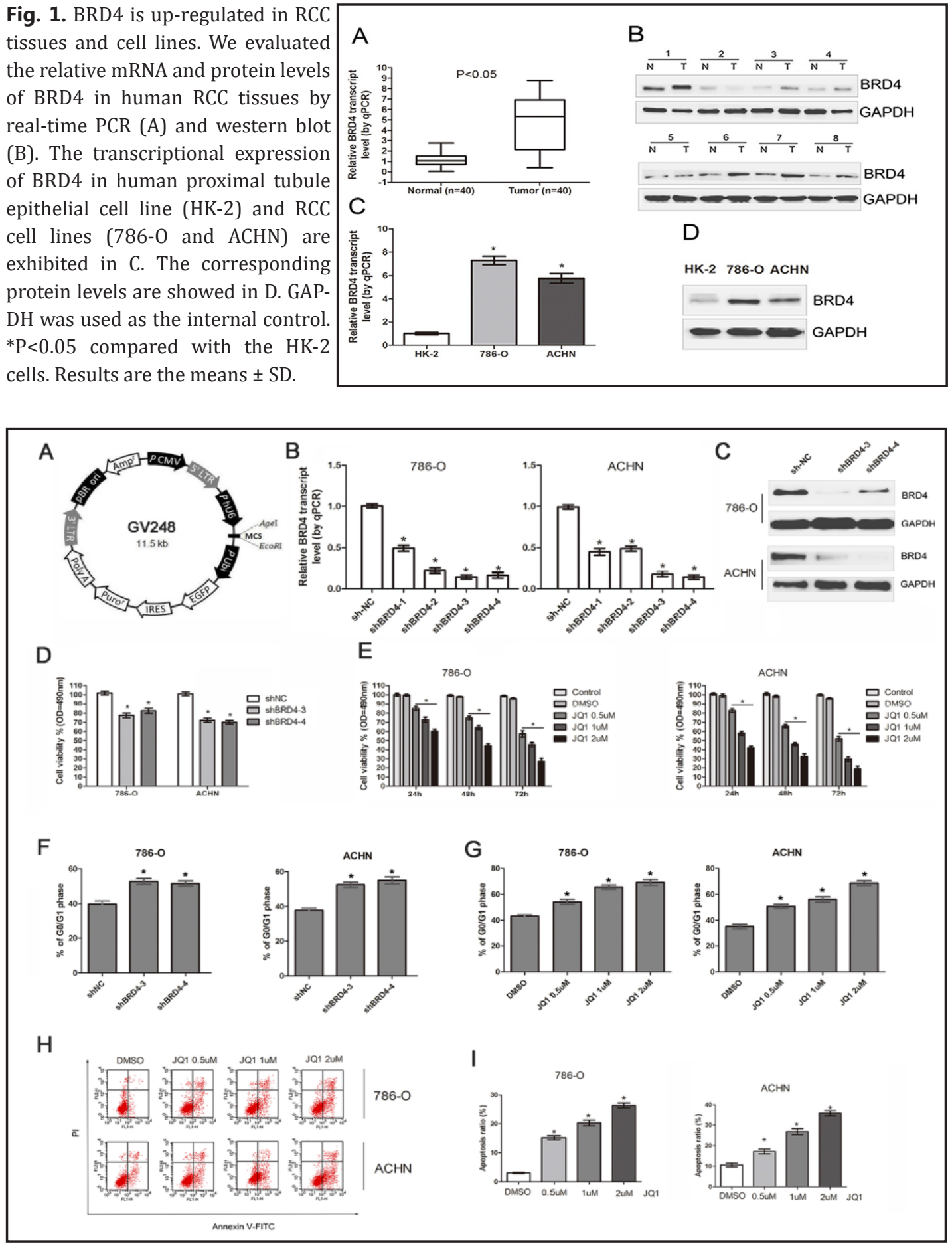

Fig. 2. BRD4 inhibition suppressed cell proliferation and induced cell apoptosis in RCC cells. The shRNAs targeting BRD4 were synthesized and digested with restriction enzymes Age I and EcoR I, and then ligated to the restriction sites of GV248 vector (A). BRD4 mRNA (B) and protein (C) expression levels $48 \mathrm{~h}$ after shRNAs transfection in 786-O and ACHN cells. Cell viability assay by MTT method was carried out $48 \mathrm{~h}$ after shBRD4 transfection in both RCC cell lines(D). And cell viability at $24 \mathrm{~h}, 48 \mathrm{~h}, 72 \mathrm{~h}$ of treatment by various concentrations $(0.5 \mu \mathrm{M}, 1 \mu \mathrm{M}, 2 \mu \mathrm{M})$ of JQ1 was assayed (E). Flow cytometry indicated that inhibition of BRD4 resulted in cell cycle arrest at G0/G1 phase (F and G), and JQ1 promoted cell apoptosis in 786-O and ACHN cells ( $\mathrm{H}$ and $\mathrm{I}$ ) as compared with the corresponding control group. ${ }^{*} \mathrm{P}<0.05$ compared with the negative control. Results are the means \pm SD. 


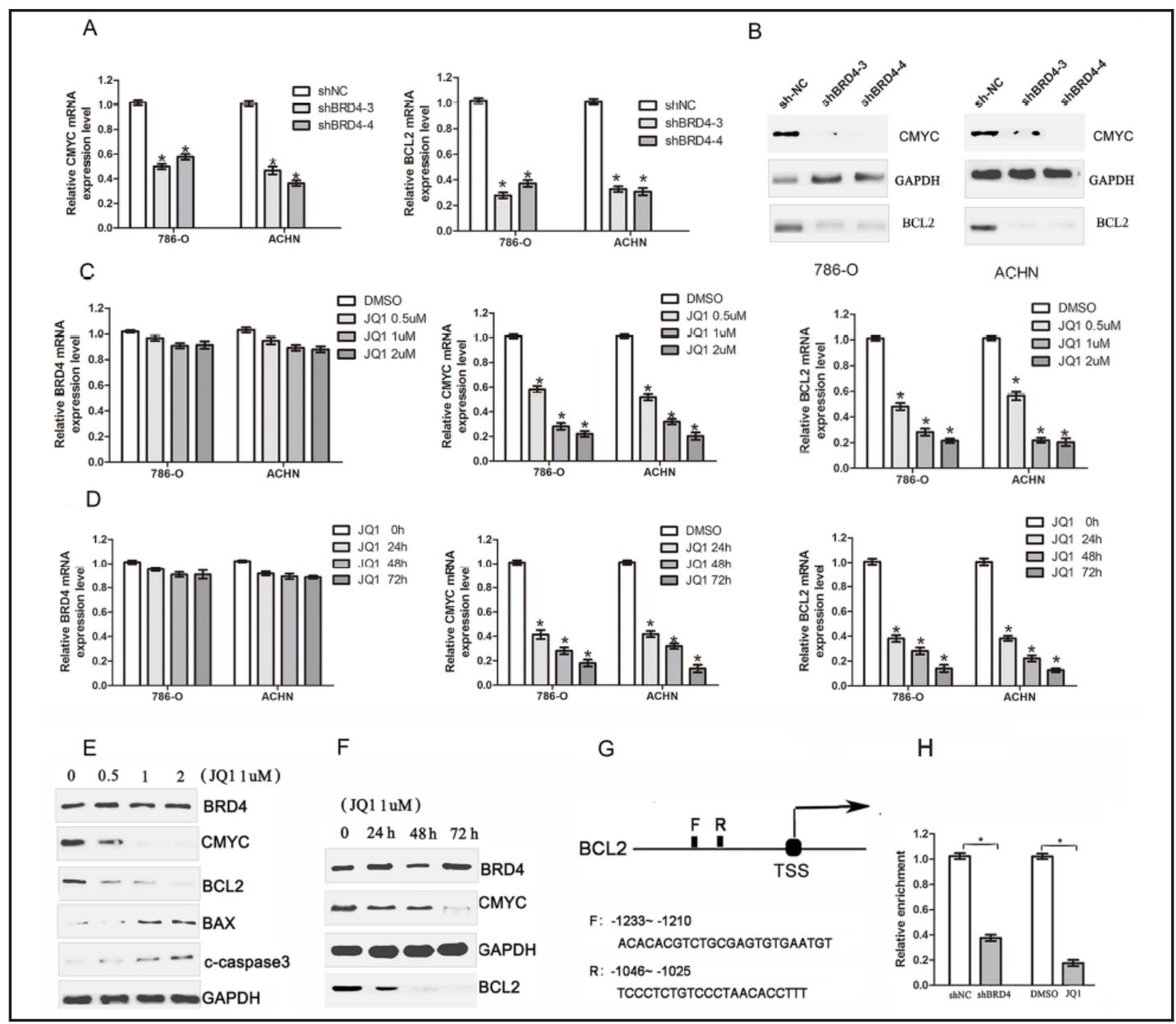

Fig. 3. BRD4 inhibition resulted in down-regulation of BCL2 and C-MYC and up-regulation of apoptosis-associated proteins. BRD4 knockdown suppressed BCL2 and C-MYC mRNA and protein levels in 786-0 and ACHN cells (A and B). JQ1 treatment decreased the mRNA and protein levels of BCL2 and C-MYC but not BRD4 at $24 \mathrm{~h}, 48 \mathrm{~h}, 72 \mathrm{~h}$ with various concentrations $(0.5 \mu \mathrm{M}, 1 \mu \mathrm{M}, 2 \mu \mathrm{M})(\mathrm{C}, \mathrm{D}, \mathrm{E}$ and F). Protein levels of cleaved-caspase3 (c-caspase3) and BAX were upregulated upon JQ1 treatment (E). The location of primers for BCL2 promoter was shown(G). CHIP experiments demonstrated that inhibition of BRD4 using shRNA and JQ1 treatment decreased the enrichment of BRD4 in BCL2 promoter region $(\mathrm{H})$. ${ }^{*} \mathrm{P}<0.05$ compared with the negative control. Results are the means \pm SD.

JQ1 treatment, MTT colorimetric assay was carried out, the results demonstrated that BRD4 knockdown or JQ1 treatment decreased cell viability in RCC cells (Fig. 2, D and E). Furthermore, cell viability was inhibited by JQ1 in a dose- and time-dependent manner. Additionally, inhibition of BRD4 induced cell cycle arrest at G0/G1 phase (Fig. 2, F and G), administration of JQ1 promoted cell apoptosis in 786-O and ACHN cell lines (Fig. 2, H and I). These result demonstrated that inhibition of BRD4 could influence 786-O and ACHN cell biological activity, indicating a pro-tumor role for BRD4 in RCC progression.

\section{Inhibition of BRD4 suppresses BCL2 and C-MYC expression and activates pro-apoptosis} protein

Previous studies have demonstrated that BCL2 and C-MYC are downstream effecters of BRD4 and are associated with cancer development. To determine whether BRD4 engages to regulate the expression levels of BCL2 and C-MYC in RCC, we respectively transfected shBRD4-3 and shBRD4-4 into 786-0 and ACHN cells for further study. As shown in Figure 3 (A and B), both shBRD4-3 and shBRD4-4 significantly down-regulated BCL2 and C-MYC 
Fig. 4. BRD4 inhibition impaired tumor growth in vivo. The tumor volume curve after shBRD4 (A) or JQ1 treatment (B). The tumor weights were reduced after shBRD4 (C) or JQ1 treatment (D). Tumors were exhibited in E. The mRNA levels of BRD4, C-MYC and BCL2 in tumors were showed in $\mathrm{F}$ and $\mathrm{G}$. The protein levels of BRD4, C-MYC and BCL2 in tumors were showed in $\mathrm{H}$ and $\mathrm{I}$. ${ }^{*} \mathrm{P}<0.05$ compared with the negative control. Results are the means \pm SD.

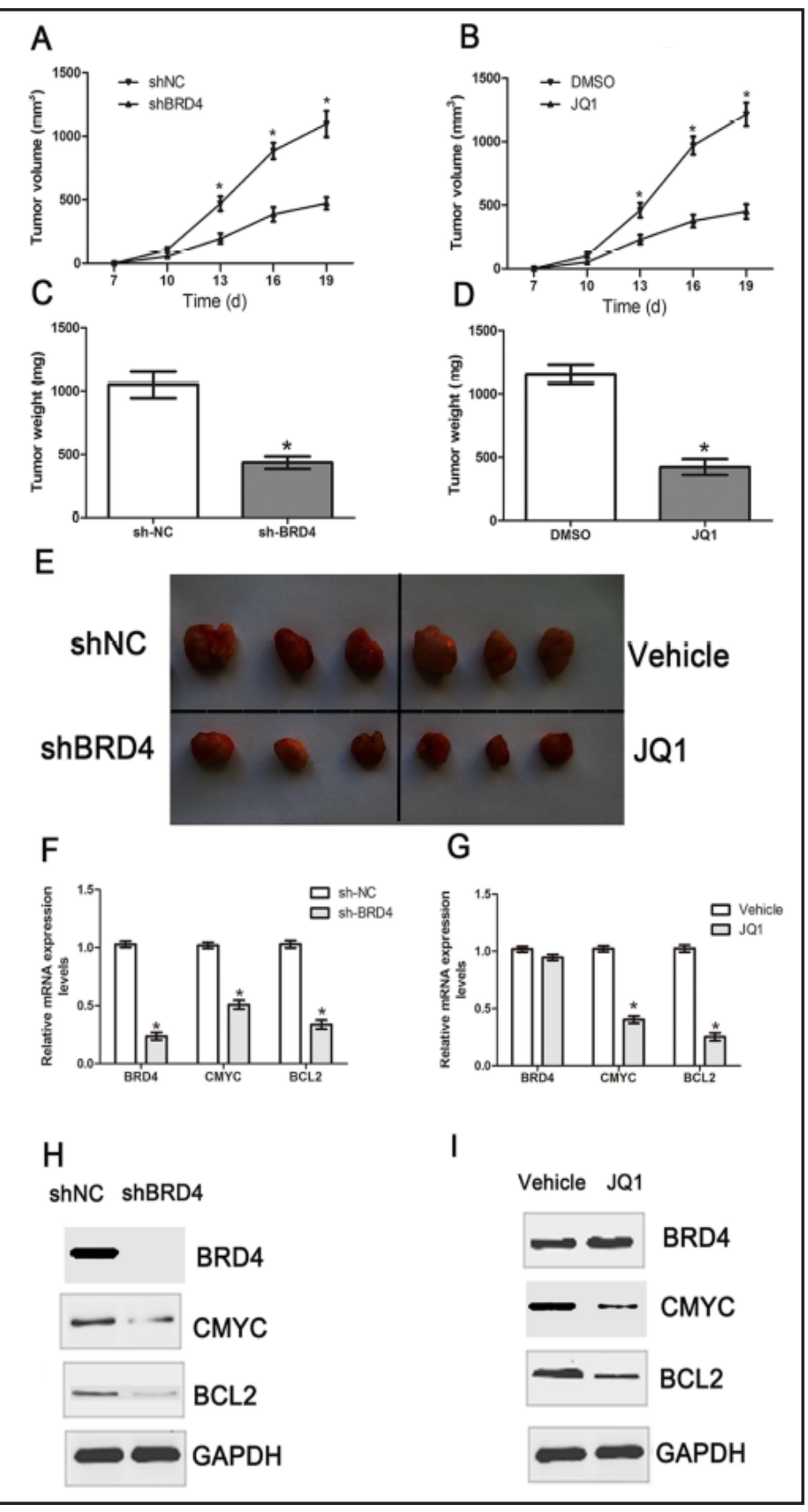

mRNA and protein levels as compared with control. BCL2 and C-MYC mRNA and protein levels but not BRD4 were markedly decreased upon JQ1 treatment. JQ1 decreased BCL2 and C-MYC expressions in a dose- and time- manner (Fig. 3, C-F). In addition, treatment with JQ1 increased the protein levels of BAX and cleaved caspase3 (Fig. 3 E). Furthermore, transfection of shBRD4 or JQ1 treatment decreased the recruitment of BRD4 to BCL2 promoter through CHIP experiments (Fig. 3, G and H). These results demonstrated that BRD4 could influence cell biological activity through regulates BCL2 and C-MYC expressions in RCC.

Knockdown of BRD4 or JQ1 impairs RCC tumor growth in vivo

To determine the antitumor effect of BRD4 inhibition in vivo, we further evaluated the effects of BRD4 inhibition in xenograft mouse models. For shBRD4 experiments, stable ACHN cells transfected with shBRD4 or control constructs were subcutaneously injected into the 


\section{Cellular Physiology Cell Physiol Biochem 2017;41:1947-1956

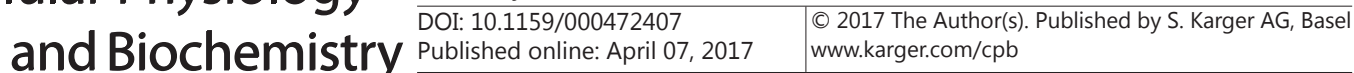

Wu et al.: BRD4 is a Novel Therapeutic Target in RCC

flanks of mice. ShBRD4 injected mice exhibited a reduction in tumor weigh and tumor size compared with their negative control groups at termination ( $\mathrm{P}<0.05$, Fig. 4 A, C and E). JQ1treatment mice also achieved a remarkable reduction in tumor weight and tumor size at the end of the experiment $(\mathrm{P}<0.05$, Fig. $4, \mathrm{~B}, \mathrm{D}$ and $\mathrm{E})$. Histologic analysis of tumors revealed a close correlation between BRD4 and BCL2 as well as C-MYC expression in control and shBRD4 or JQ1 cohorts (Fig. 4 F-I), suggesting that BRD4 supports a pro-tumor advantage. These data further identified BRD4 as a critical contributor to tumor growth and strengthen inhibition of BRD4 as a plausible treatment strategy against RCC.

\section{Discussion}

BRD4 is a highly conserved and well-known epigenome reader, and has been considered to be a key transcription regulator in dividing cells. BRD4 could interact with P-TEFb and recruit several transcriptional regulatory complexes to specific chromatin region $[13,19]$. In addition, BRD4 engages in regulatory interactions with several histone modifiers and DNAbinding transcription factors to exert its relevant functions [19-22]. Aberrant expression of BRD4 protein is increasingly detected in a series of cancer types and has been reported to significantly influence tumor progression. For example, BRD4 is significantly upregulated in glioblastoma tumors and exerts a pro-oncogenic function in that context [23]. In colon cancer and breast cancer, BRD4 was reported to downregulated and probably serve as a tumor suppressor $[11,14]$. In addition, BRD4-NUT fusion in squamous cell carcinomas could result in a prooncogenic phenotype, which is responsible for mid-line carcinomas [24, 25]. The findings that deregulation of BRD4 could influence cancer cell biological activity in a series of cancer types supply the rationale to assess the expression and function of BRD4 in RCC. Our results strongly demonstrate that BRD4 is highly expressed in RCC tissues and cells, which indicates that BRD4 is probably associated with tumor progression. In addition, the expression level of BRD4 in RCC was significantly associated with histological stage and lymph node metastasis, suggesting that BRD4 is associated with tumor development and potentially promote tumor invasion. Furthermore, we found that knockdown of BRD4 using shRNAs repressed cell viability and suppressed tumor growth, indicating an important role of BRD4 in controlling RCC biological activity. These results would facilitate our further understanding of the underlying biology and molecular pathology, which has not been described previously.

To date, RCC remains an intractable social and medicine problem. Early stage patients with localized tumors generally have a favorable prognosis after surgical resection of the primary tumor. However, a considerable proportion of patients with RCC already have metastatic disease at diagnosis [26]. RCC is unusually resistant to chemotherapy and radiotherapy compared to other solid tumors, and novel immunotherapies have supplied some limited benefits for patients who suffer from advanced RCC [27-30]. Therefore, alternative therapeutic strategies are still necessary to be explored to increase the survival rate of patients with RCC.

Currently, treatment therapies to manipulate BET proteins are emerging. Recent studies have proved that pharmacologic suppression of BET/acetylated histone binding impacts cell apoptosis, differentiation or tumor growth in several disease models include melanoma [12], multiple myeloma [17], osteosarcoma [31], prostate cancer [32] and acute myeloid leukemia [33]. Given our observation that BRD4 is overexpressed in human RCC tissues and cell lines, we hypothesized that inhibition of BRD4 could influence RCC cell biological activity. Using a first-class small-molecule BRD4 inhibitor JQ1, we demonstrated that JQ1 inhibited cell proliferation, induced cell apoptosis and suppressed tumor growth in vitro and in vivo, which was similar to the effects observed upon shRNA-mediated BRD4 knockdown. These results further identify BRD4 as an important regulator in RCC and supply the rationale to use BET inhibitor for RCC treatment, which would be helpful for patients with RCC. In addition, our results demonstrated that inhibition of BRD4 influenced cell biological activity 
mainly through repressing BCL2 and C-MYC expression and activating a group of apoptosisassociated protein kinases, which is consistent with previous studies [34]. It has been reported that several target therapies such as vascular endothelial growth factor (VEGF) or mTOR inhibitors have exhibited some efficacy in RCC treatment [35-37], it will be interesting to explore the potential relationship between BRD4 inhibitor and other target therapies and compare the effects of these novel treatment strategies in the future.

In summary, our study demonstrates the aberrant expression and prooncogenic role of BRD4 in RCC, and supply the rationale to applying BET inhibitor for RCC treatment. Our results enrich the knowledge about the molecular mechanism and target therapies in RCC, which is thus potentially helpful to patients with RCC.

\section{Disclosure Statement}

The authors declare no conflict of interest.

\section{References}

1 Siegel R, Naishadham D, Jemal A: Cancer statistics, 2013. CA Cancer J Clin 2013;63:11-30.

-2 Rini BI, Campbell SC, Escudier B: Renal cell carcinoma. Lancet 2009;373:1119-1132.

3 Janowitz T, Welsh SJ, Zaki K, Mulders P, Eisen T: Adjuvant therapy in renal cell carcinoma-past, present, and future. Semin Oncol 2013;40:482-491.

4 Ljungberg B, Cowan NC, Hanbury DC, Hora M, Kuczyk MA, Merseburger AS, Patard JJ, Mulders PF, Sinescu IC: EAU guidelines on renal cell carcinoma: the 2010 update. Eur Urol 2010;58:398-406.

5 Li X, Xin S, He Z, Che X, Wang J, Xiao X, Chen J, Song X: MicroRNA-21 (miR-21) post-transcriptionally downregulates tumor suppressor PDCD4 and promotes cell transformation, proliferation, and metastasis in renal cell carcinoma. Cell Physiol Biochem 2014;33:1631-1642.

6 Dhalluin C, Carlson JE, Zeng L, He C, Aggarwal AK, Zhou MM: Structure and ligand of a histone acetyltransferase bromodomain. Nature 1999;399:491-496.

7 Belkina AC, Denis GV: BET domain co-regulators in obesity, inflammation and cancer. Nat Rev Cancer 2012;12:465-477.

-8 Matzuk MM, McKeown MR, Filippakopoulos P, Li Q, Ma L, Agno JE, Lemieux ME, Picaud S, Yu RN, Qi J, Knapp S, Bradner JE: Small-molecule inhibition of BRDT for male contraception. Cell 2012;150:673-684.

-9 Sanchez R, Zhou MM: The role of human bromodomains in chromatin biology and gene transcription. Curr Opin Drug Discov Devel 2009;12:659-665.

10 Huang B, Yang XD, Zhou MM, Ozato K, Chen LF: Brd4 coactivates transcriptional activation of NF-kappaB via specific binding to acetylated RelA. Mol Cell Biol 2009;29:1375-1387.

11 Crawford NP, Alsarraj J, Lukes L, Walker RC, Officewala JS, Yang HH, Lee MP, Ozato K, Hunter KW: Bromodomain 4 activation predicts breast cancer survival. Proc Natl Acad Sci U S A 2008;105:6380-6385.

-12 Segura MF, Fontanals-Cirera B, Gaziel-Sovran A, Guijarro MV, Hanniford D, Zhang G, Gonzalez-Gomez P, Morante M, Jubierre L, Zhang W, Darvishian F, Ohlmeyer M, Osman I, Zhou MM, Hernando E: BRD4 sustains melanoma proliferation and represents a new target for epigenetic therapy. Cancer Res 2013;73:62646276.

13 Jang MK, Mochizuki K, Zhou M, Jeong HS, Brady JN, Ozato K: The bromodomain protein Brd4 is a positive regulatory component of P-TEFb and stimulates RNA polymerase II-dependent transcription. Mol Cell 2005;19:523-534.

-14 Rodriguez RM, Huidobro C, Urdinguio RG, Mangas C, Soldevilla B, Dominguez G, Bonilla F, Fernandez AF, Fraga MF: Aberrant epigenetic regulation of bromodomain BRD4 in human colon cancer. J Mol Med (Berl) 2012;90:587-595.

15 Prinjha RK, Witherington J, Lee K: Place your BETs: the therapeutic potential of bromodomains. Trends Pharmacol Sci 2012;33:146-153. 


\section{Cellular Physiology Cell Physiol Biochem 2017;41:1947-1956

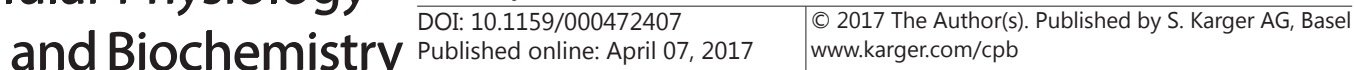

Wu et al.: BRD4 is a Novel Therapeutic Target in RCC

16 Filippakopoulos P, Qi J, Picaud S, Shen Y, Smith WB, Fedorov O, Morse EM, Keates T, Hickman TT, Felletar I, Philpott M, Munro S, McKeown MR, Wang Y, Christie AL, West N, Cameron MJ, Schwartz B, Heightman TD, La Thangue N, French CA, Wiest O, Kung AL, Knapp S, Bradner JE: Selective inhibition of BET bromodomains. Nature 2010;468:1067-1073.

17 Delmore JE, Issa GC, Lemieux ME, Rahl PB, Shi J, Jacobs HM, Kastritis E, Gilpatrick T, Paranal RM, Qi J, Chesi M, Schinzel AC, McKeown MR, Heffernan TP, Vakoc CR, Bergsagel PL, Ghobrial IM, Richardson PG, Young RA, Hahn WC, Anderson KC, Kung AL, Bradner JE, Mitsiades CS: BET bromodomain inhibition as a therapeutic strategy to target c-Myc. Cell 2011;146:904-917.

18 Lockwood WW, Zejnullahu K, Bradner JE, Varmus H: Sensitivity of human lung adenocarcinoma cell lines to targeted inhibition of BET epigenetic signaling proteins. Proc Natl Acad Sci U S A 2012;109:19408-19413.

19 Rahman S, Sowa ME, Ottinger M, Smith JA, Shi Y, Harper JW, Howley PM: The Brd4 extraterminal domain confers transcription activation independent of pTEFb by recruiting multiple proteins, including NSD3. Mol Cell Biol 2011;31:2641-2652.

20 Wu SY, Lee AY, Lai HT, Zhang H, Chiang CM: Phospho switch triggers Brd4 chromatin binding and activator recruitment for gene-specific targeting. Mol Cell 2013;49:843-857.

21 Liu W, Ma Q Wong K, Li W, Ohgi K, Zhang J, Aggarwal AK, Rosenfeld MG: Brd4 and JMJD6-associated antipause enhancers in regulation of transcriptional pause release. Cell 2013;155:1581-1595.

22 Shi J, Wang Y, Zeng L, Wu Y, Deng J, Zhang Q, Lin Y, Li J, Kang T, Tao M, Rusinova E, Zhang G, Wang C, Zhu H, Yao J, Zeng YX, Evers BM, Zhou MM, Zhou BP: Disrupting the interaction of BRD4 with diacetylated Twist suppresses tumorigenesis in basal-like breast cancer. Cancer Cell 2014;25:210-225.

23 Pastori C, Daniel M, Penas C, Volmar CH, Johnstone AL, Brothers SP, Graham RM, Allen B, Sarkaria JN, Komotar RJ, Wahlestedt C, Ayad NG: BET bromodomain proteins are required for glioblastoma cell proliferation. Epigenetics 2014;9:611-620.

-24 French C: NUT midline carcinoma. Nat Rev Cancer 2014;14:149-150.

-25 French CA, Miyoshi I, Kubonishi I, Grier HE, Perez-Atayde AR, Fletcher JA: BRD4-NUT fusion oncogene: a novel mechanism in aggressive carcinoma. Cancer Res 2003;63:304-307.

26 Motzer RJ, Bander NH, Nanus DM: Renal-cell carcinoma. N Engl J Med 1996;335:865-875.

27 Yoshimura K, Uemura H: Role of vaccine therapy for renal cell carcinoma in the era of targeted therapy. Int J Urol 2013;20:744-755.

28 Negrier S, Escudier B, Lasset C, Douillard JY, Savary J, Chevreau C, Ravaud A, Mercatello A, Peny J, Mousseau M, Philip T, Tursz T: Recombinant human interleukin-2, recombinant human interferon alfa-2a, or both in metastatic renal-cell carcinoma. Groupe Francais d'Immunotherapie. N Engl J Med 1998;338:1272-1278.

29 Jantzer P, Schendel DJ: Human renal cell carcinoma antigen-specific CTLs: antigen-driven selection and long-term persistence in vivo. Cancer Res 1998;58:3078-3086.

30 Coppin C, Porzsolt F, Awa A, Kumpf J, Coldman A, Wilt T: Immunotherapy for advanced renal cell cancer. Cochrane Database Syst Rev DOI: 10.1002/14651858.CD001425.pub2.

-31 Baker EK, Taylor S, Gupte A, Sharp PP, Walia M, Walsh NC, Zannettino AC, Chalk AM, Burns CJ, Walkley CR: BET inhibitors induce apoptosis through a MYC independent mechanism and synergise with CDK inhibitors to kill osteosarcoma cells. Sci Rep DOI: 10.1038/srep10120.

-32 Asangani IA, Dommeti VL, Wang X, Malik R, Cieslik M, Yang R, Escara-Wilke J, Wilder-Romans K, Dhanireddy S, Engelke C, Iyer MK, Jing X, Wu YM, Cao X, Qin ZS, Wang S, Feng FY, Chinnaiyan AM: Therapeutic targeting of BET bromodomain proteins in castration-resistant prostate cancer. Nature 2014;510:278-282.

-33 Zuber J, Shi J, Wang E, Rappaport AR, Herrmann H, Sison EA, Magoon D, Qi J, Blatt K, Wunderlich M, Taylor MJ, Johns C, Chicas A, Mulloy JC, Kogan SC, Brown P, Valent P, Bradner JE, Lowe SW, Vakoc CR: RNAi screen identifies Brd4 as a therapeutic target in acute myeloid leukaemia. Nature 2011;478:524-528.

-34 Fung JJ, Kosaka A, Shan X, Danet-Desnoyers G, Gormally M, Owen K: Registered report: Inhibition of BET recruitment to chromatin as an effective treatment for MLL-fusion leukemia. eLife 2015;4:529-533.

-35 Abe H, Kamai T: Recent advances in the treatment of metastatic renal cell carcinoma. Int J Urol 2013;20:944-955.

-36 Mittal K, Rini B: Kidney cancer in 2012: new frontiers in kidney cancer research. Nat Rev Urol 2013;10:7072.

37 Mattei J, da Silva RD, Sehrt D, Molina WR, Kim FJ: Targeted therapy in metastatic renal carcinoma. Cancer Lett 2014;343:156-160. 